and in effect avoids, is the whole series of controversies that underlie this apparently seamless synthesis. Greenberg's linguistic groupings have been criticized by many linguists, and this may be one reason why the author has very little to say about the Americas before Columbus.

I myself had one severe criticism of Diamond's The Third Chimpanzee, where I thought he misinterpreted the evidence for the domestication of the horse, setting the date of that domestication earlier than the current data allow, and confusing its early exploitation for food production around $4000 \mathrm{BC}$ with the role of the mounted warrior in military conflict, which did not emerge until after $1500 \mathrm{BC}$ and thus after the princely use of the horse-drawn chariot that is so clearly documented in the Near East and in the Mycenaean world. This may be one reason why his treatment of Europe (which is lumped together in a single chapter with the Americas) is sketchy. Another could be the current and very interesting disagreement among geneticists involving the notion of a significant population diffusion into Europe with the dispersal of farming (the 'demic diffusion' model of Cavalli-Sforza and his associates) being called into question by researchers at Oxford using data from mitochondrial DNA, only to be re-asserted by Pääbo and others who suggest that the effective mutation rate of the relevant mitochondrial DNA 'hot-spots' may have been gravely underestimated. (See L. L. Cavalli-Sforza, P. Menozzi and A. Piazza, Science 259, 639-646, 1993; M. Richards et al., Am. J. Hum. Genet. 59, 185-203, 1996; and S. Pääbo, Am. J. Hum. Genet. 59, 493-496, 1996.)

Others may be critical of the limited role that is here expressly assigned to the operation of specifically human cognitive abilities. For there is little discussion about the differing natures of the cultures seen on the different continents: why Aztec culture took the form it did or why Chinese civilization differed from that of ancient Egypt.

There may, at first sight, be little in this book for the current school of 'post-processual' archaeologists, with their emphasis upon the uniqueness of each human society and their reluctance to make generalizations about human history. But to accept this would be to overlook the book's greatest strengths. It is willing to simplify and to generalize; and it does reach conclusions, about ultimate as well as proximate causes, that carry great conviction, and that have rarely, perhaps never, been stated so coherently and so effectively before. For that reason, and with few reservations, this book may be welcomed as one of the most important and readable works on the human past published in recent years.

Colin Renfrew is director of the McDonald Institute for Archaeological Research, Downing Street, Cambridge CB2 3ER, UK.

\section{Hitch-hiker's guide to the Solar System}

The NASA Atlas of the Solar System

by Ronald Greeley and Raymond Batson

Cambridge University Press: 1997. Pp. 369.

$\$ 150, £ 100$

\section{CariD. Murray}

By any criteria, the comprehensive exploration of our Solar System has to be regarded as one of the major scientific achievements of the century, if not the millennium. In the 40 years since the launch of Sputnik 1, a fewgenerations have been privileged to witness the first images from the surface of the Moon, Mars and Venus, as well as in situ data returned from the robotic spacecraft that have visited all the planets from Mercury to Neptune.

For technical achievement and sheer audacity of purpose, the highlights of this exploration have to include the results from the two Voyager missions to the outer Solar System. In the 12 years after their launch in 1977 , these NASA spacecraft have provided close-up images of Jupiter, Saturn, Uranus and Neptune and of their attendant moons and ring systems. Without such successful NASA missions, any attempt to produce a Solar System atlas would be as pointless as publishing a world atlas but restricting it to maps of Europe.

There is probably no ideal time to produce an atlas of the Solar System. With spacecraft such as Mars Pathfinder and Mars Global Surveyor about to provide another order-of-magnitude increase in our knowledge of one planet, and with the Cassini-Huygens mission to Saturn waiting in the wings, a delay of another decade or so would produce a more complete work. However, the natural pause produced by the end of the radar mapping of Venus by Magellan, and the full analysis of the data from the Galileo spacecraft orbiting Jupiter, means that now is as good a time as any to undertake this ambitious project.

The understated goal is "to provide a set of maps of uniform format and consistent scales, organised by planetary system for all of the objects seen thus far". This is a massive undertaking and, thanks to the map-making skills of the US Geological Survey, the results are truly spectacular.

Although the authors make no claim to have produced a textbook, the atlas is much more than a collection of maps. As well as a general introduction, background information is provided for each planetary system, complete with colourful, informative diagrams and clear explanations. Every solid surface that has been viewed with sufficient resolution has its corresponding geological, reference and shaded relief map, with the occasional bonus of a colour photo mosaic for objects such as Mars, Io, Europa and Triton. For reasons of clarity, not all features are named on all maps, but the atlas includes a complete gazetteer listing every named feature from Aananin (a crater on the Saturnian moon Rhea) to Zwicky (a lunar crater), together with its latitude and longitude on the respective body and a brief description of the name's origin.

This is a reference book par excellence. The design is superb, with the uniform format making it easy to carry out comparative planetology. Small touches such as the outlines of planetary orbits at the top of the page are particularly helpful, with the orbit of the current system highlighted for the browser

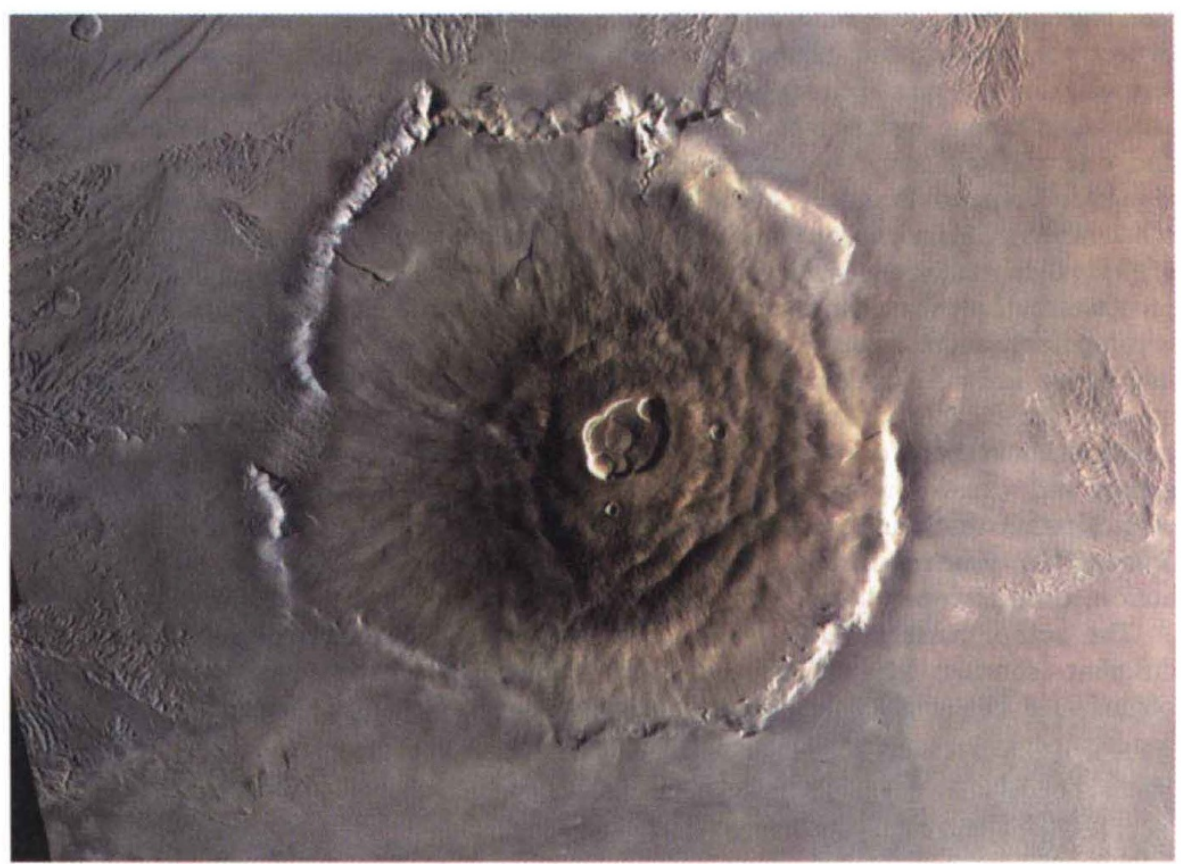

The martian volcano Olympus Mons, photographed by Viking Orbiter. 
— the atlas's equivalent of 'you are here'.

Some features do not work so well. There is a valiant attempt to use a series of colourful strips with different scales to illustrate the locations of the wide range of orbits within a given planetary system, but the result is confusing. There are also the inevitable minor errors and inconsistencies associated with such an enormous enterprise. The most glaring mistake is that the relief map of the Neptunian moon Triton is labelled "Titania", the name of a much smaller and less interesting Uranian satellite; perhaps we can be generous and attribute this to the action of some mischievous spirit.

The sheer size of Greeley and Batson's finished product makes it difficult to lift, thereby reinforcing the impression that this is a reference work. There are inevitable comparisons with the lavish world atlases from previous centuries. Even the frequent blank areas on maps of satellites and planets regions not imaged during brief spacecraft fly-bys - are reminiscent of the labelling by map-makers of large tracts of land in Earth's Southern Hemisphere as "Terra Incognita". While some might feel cheated by paying good money for empty space, such regions are a sobering reminder of our level of ignorance and the exciting task of exploration that lies ahead.

In a few decades, the blanks will be filled in by the next generation of explorers, both robot and human. Until then, this atlas will serve as the definitive guide to the Solar System and a fitting testimony to NASA's achievements in this field.

Carl Murray is in the Astronomy Unit, Queen Mary and Westfield College, University of London, London E1 4NS, UK.

\section{Custom-made beast of burden}

The Nature of Horses: Exploring Equine Evolution, Intelligence and Behavior

by Stephen Budiansky

Free Press: 1997. Pp. 261. $\$ 30$

\section{Horses Through Time}

Edited by Sandra L. Olsen

Roberts Rinehart: 1996. Pp. 222. \$35.

Distributed in the UK by Airlift Books, $£ 25$ Marian Stamp Dawkins

It is definitely an exaggeration to claim, as the blurb to Stephen Budiansky's The Nature of Horses does, that the book contains "everything horse lovers, novice riders, and professional trainers alike need to know about one of our most beloved and fascinating animals". There are no instructions about how to train horses, for example, or what to feed them on, but there are nevertheless some fascinating facts and ideas. One

\section{IMAGE UNAVAILABLE FOR COPYRIGHT REASONS}

Not a horse chestnut, but Mares by an Oak Tree by George Stubbs.

of the most memorable is Budiansky's view that the horse, being a large mammal vulnerable to climate change, would have become extinct at the end of the Ice Age as many other species did, were it not for domestication by humans. North America, which had been the cradle of equid evolution for 55 million years, had no horses by 10,000 years ago; they were reintroduced by Christopher Columbus in 1494 . The American Indians, who had never seen the animals before but subsequently of course made famous use of them, called them 'big dogs'.

The horse as we know it was probably domesticated in the Ukraine about 6,000 years ago. Budiansky argues that it was brought back, quite literally, from the brink of extinction by happy accidents of history that produced an animal preadapted for human use. The horse has a social system with rules of dominance and subordination that makes it particularly tractable for obeying humans; it is capable of carrying heavy burdens over long distances; it has a fortunate lack of horns or antlers; and it even possesses a convenient gap in its cheek teeth where humans can place a bit. Instead of becoming extinct, the animal made an explosive comeback by 4,000 years ago, so horse remains are common in archaeological sites from Asia to Britain.

The book contains some informative, if not particularly original, chapters on the animal's sensory system, and useful descriptions of gaits and the way the horse manages to be so large yet so fast. The horse-racing fraternity comes in for some criticism for its lack of understanding of genetics. The Jockey Club in America, for example, refuses to register horses that have been bred through artificial insemination or embryo transplants. Racing thoroughbreds are inbred anyway, so it is hardly surprising that attempts at breeding horses to race faster have not been very successful. In fact, speed records for the animals have remained virtually unchanged for the past 50 years, despite meticulous attention to stud books and breeding. Budiansky recommends opening up horse-racing to all breeds, with the prediction that cross-bred horses would soon be leaving the thoroughbreds behind.

While Budiansky's book is well-written, full of useful information and certainly enjoyable, I found myself vaguely annoyed by two things.

One was the point already mentioned: that the book simply did not live up to its claim to cover everything one might want to know about horses. I would have thought, for example, that any book that dealt with human-horse relationships should have offered more on the different ways of training horses, from the time-honoured ways of subduing them to the newer ways which involve establishing a rapport with a social equal. Some of the claims that have been made for these new methods are spectacular (the Queen is said to be impressed with them). But do they work?

The second was that much of his writing draws upon the work or other people, and it is sometimes difficult to know whether the ideas are his own or not. This concern is particularly obvious if one reads Budiansky's book, as I did, soon after reading Horses Through Time, edited by Sandra Olsen. Budiansky not only draws heavily on the work of several of the authors in the latter book but even uses several of the same photographs, such as one of an Assyrian frieze and a particularly dramatic one of a horseskin suspended on a pole.

Olsen's book has an altogether different flavour, even though it covers much of the same ground and is concerned with the evolution and domestication of the horse as well as its continuing relationship with humans. It contains ten different essays by nine different authors, giving it the inevitably slightly disjointed feel from which any multiauthored volume is liable to suffer.

There are some excellent and well illustrated chapters, including an authoritative description by Richard Hulbert of the horse's ancestry, and others on what is 